\title{
Diagnostic and prognostic features in adrenocortical carcinoma: a single institution case series and review of the literature
}

\author{
Kerollos N Wanis ${ }^{1}$ and Rani Kanthan $2,3^{*}$
}

\begin{abstract}
Background: Adrenocortical carcinoma is a rare cancer, with an incidence in the literature of 0.5 to 2 cases per million population per year. Adult adrenocortical carcinoma has a poor prognosis, underscoring the importance of identifying diagnostic and prognostic markers.

Methods: We searched our laboratory database for all cases in the past 15 years with a diagnosis of adrenocortical carcinoma. The original slides were then reviewed for their histopathological features. A representative paraffin block was subjected to further immunohistochemical staining for Ki-67, inhibin, steroidogenic factor-1 (SF-1), p53, and B-catenin. These slides were scored by the study pathologist who was blinded to all clinicopathological data. In addition, a comprehensive review of the relevant English literature in the past 15 years was conducted.

Results: Eight cases were identified, including two adrenal sarcomatoid carcinomas. Seven of the eight cases had a disrupted reticulin network. Six of the eight tumors had $>10 \%$ Ki-67 expression. Five of the eight tumors had $>10 \%$ p53 expression. Positive inhibin immunohistochemical staining was seen in three of the eight tumors, and positive SF-1 staining was seen in five of the seven stained tumors. Abnormal B-catenin intracellular accumulation was noted in four of the eight tumors. The two tumors in our series with sarcomatoid histology did not stain positively for SF-1 or inhibin.

Conclusions: Eight cases of adrenocortical carcinoma, including two with sarcomatoid features are presented. The two sarcomatoid adrenocortical carcinomas in our series did not stain for SF-1 which suggests a possible de novo pathway of tumorigenesis for this rare variant. The reticulin staining method was a useful tool for rapid differentiation of adrenocortical adenomas and carcinomas. Diffuse p53 staining showed a trend for positive correlation with increased Ki-67 expression. Inhibin staining was inconsistently expressed in our cases of adrenocortical carcinoma. In conclusion, as adrenocortical carcinoma is a rare disease, we recommend future multicenter studies with appropriate sample sizes to further evaluate the efficacy of these diagnostic and prognostic markers.
\end{abstract}

Keywords: Adrenocortical carcinoma, Sarcomatoid carcinoma, Immunohistochemistry, Reticulin, Diagnosis

\section{Background}

Adrenocortical carcinoma (ACC) is rare and has a poor prognosis. Even for patients with resected tumors, the median survival is only 32 months in the United States [1]. While ACC is uncommon with an annual incidence of 0.5 to 2.0 per million people, adrenal incidentalomas

\footnotetext{
* Correspondence: rani.kanthan@saskatoonhealthregion.ca

${ }^{2}$ Department of Pathology and Laboratory Medicine, University of

Saskatchewan, Saskatoon, Canada

${ }^{3}$ Royal University Hospital, Room 2868G-Wing, 103 Hospital Drive, Saskatoon,

Saskatchewan S7N OW8, Canada

Full list of author information is available at the end of the article
}

are increasingly being recognized, due to the availability of superior imaging techniques, with a reported prevalence of $3 \%$ to $4 \%$ on abdominal CT scan [1-5]. Most adrenal incidentalomas are benign, while most malignant adrenal tumors are metastatic in origin [6]. As such, accurate diagnosis of malignant adrenocortical tumors, particularly distinguishing ACC from adrenal adenomas, is essential for management; however, accurate diagnosis continues to remain a challenge. There are continued significant areas of uncertainty regarding pathogenesis and risk assessment. In this context, several histopathological and

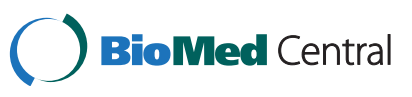


immunohistochemical markers have emerged in the past two decades as additional adjuncts that include markers, such as steroidogenic factor-1 (SF-1) that may be useful in establishing the adrenocortical origin of an adrenal mass, while other markers, such as Ki-67 and p53, could help stratify tumors into prognostic groups.

The aim of this study is to discuss the diagnostic and prognostic features of ACC through a series of cases treated at our institution over a 15-year period in the context of a comprehensive relevant literature review. We compared immunohistochemical expression profiles of Ki-67, inhibin, SF-1, p53, and B-catenin with histopathological features and patient outcome.

\section{Methods}

\section{Pathological review}

All patients in the Saskatoon Health Region Department of Pathology Laboratory Information System with a pathological diagnosis of adrenocortical carcinoma from 1998 to 2013 were identified. All cases were reviewed on a routine hematoxylin-eosin-stained slide according to the Weiss criteria to confirm the presence of ACC. Immunohistochemical studies using antibodies to Ki-67, B-catenin, SF-1, and p53 were performed on a representative deparaffinized tissue section by the avidin-biotinperoxidase complex $(\mathrm{ABC})$ technique after antigen retrieval using appropriate positive and negative controls in all cases. Negative controls were obtained by omission of the primary antibody from the staining procedure. The antibodies used with their sources, clones, antigen-retrieval techniques, and dilutions are listed in Table 1.

Immunohistochemically stained slides were analyzed in the standard semi quantitative basis incorporating the intensity of the staining (mild, moderate, strong) coupled with the percentage of positively stained cells in a fourpoint scale: 0 , no stain (up to $10 \%$ positive cells); 1 , light ( $11 \%$ to $25 \%$ positive cells); 2 , moderate (26\% to $50 \%$ positive cells); 3 , heavy ( $51 \%$ to $75 \%$ positive cells) and; 4 , intense stain ( $76 \%$ to $100 \%$ positive cells). The cells were considered positive when more than $10 \%$ of them were stained with the respective antibodies. The reticulin framework of the tumors was examined by histochemical staining. The study pathologist was blinded to any clinical information prior to pathological review and interpretation for the purpose of this study.

The hospital charts for all patients were obtained and data was collected on age, sex, mode of presentation of the tumor, and available follow-up.

Upon application, this study was exempt from ethical approval by the University of Saskatchewan Biomedical Ethics Review Board.

\section{Literature review}

A literature search using the National Library of Medicine Interface PubMed was conducted using the search terms 'adrenocortical carcinoma' and 'adrenal cortical carcinoma' which was limited to the English language from 1999 to present. The bibliographies of these manuscripts further identified relevant secondary sources.

A detailed review of the published large case series was undertaken. Large case series were defined as those having an ' $n$ ' greater than 300 . These were compiled for tabulation.

\section{Results}

\section{Pathological review}

From an initial search list of 15 cases of possible ACC, eight patients with a 'bonafide' histopathological diagnosis of adrenocortical carcinoma were identified using the Weiss criteria as a guideline for diagnosis. There were five females and three males with an average age at diagnosis of 53.5 years (range 25 to 79 ).

Necrosis was the most common histopathological feature, found in six of eight tumors. Vascular invasion was identified in five of eight, marked nuclear pleomorphism in two of eight, and capsular invasion in one of eight. Increased mitotic rate greater than 5/50 high-powered fields (HPFs) was seen in seven cases. Atypical mitoses were

Table 1 Antibodies used in this study

\begin{tabular}{|c|c|c|c|c|c|}
\hline Antibody & $\begin{array}{l}\text { Company and } \\
\text { clone }\end{array}$ & Target retrieval solution (TRS) & Detection & Dilution & Link to spec sheet \\
\hline $\begin{array}{l}\text { Beta } \\
\text { catenin }\end{array}$ & Dako, B-catenin-1 & High & Flex & $1: 200$ & $\begin{array}{l}\text { Monoclonal mouse anti-human beta-catenin, } \\
\text { clone } \beta \text {-catenin-1 }\end{array}$ \\
\hline Inhibin & Dako, R1 & High & Flex & $1: 5$ & Monoclonal mouse anti-human inhibin a, clone R1 \\
\hline Ki67 & Dako, MIB1 & High & Flex & $1: 50$ & $\begin{array}{l}\text { Monoclonal mouse anti-human Ki-67 antigen, } \\
\text { clone MIB-1 }\end{array}$ \\
\hline Ki67 decal & Dako, MIB1 & High & Flex & $1: 20$ & Same as above \\
\hline p53 & Dako, D0-7 & High & Flex & $1: 100$ & $\begin{array}{l}\text { Monoclonal mouse anti-human p53 protein, clone } \\
\text { DO-7 }\end{array}$ \\
\hline SF-1 & Invitrogen & $\begin{array}{l}\text { Dako3in1 high pH on Dako PT } \\
\text { instrument }\end{array}$ & $\begin{array}{l}\text { Dako-envision + } \\
\text { mouse }\end{array}$ & 1:150 & $\begin{array}{l}\text { Monoclonal mouse }[\mathrm{Mm}] \operatorname{lgG} 1 \text { anti-human clone } \\
\text { N1665 }\end{array}$ \\
\hline
\end{tabular}

$\lg \mathrm{G} 1$, immunoglobulin G1; SF-1, steroidogenic factor-1. 
easily observed in five cases. All cases had a diffuse architecture. Venous and sinusoidal invasion were present in five of the eight cases. In summary, seven cases had more than four Weiss criterion thereby meeting the histological criteria for ACC. In one case, though there was diffuse architecture with high grade nuclei and increased mitoses, diffuse necrosis, atypical mitoses, capsular, sinusoidal, or venous invasion were not identified. Reticulin staining revealed loss of the reticulin network in seven of the eight tumors. Ki-67 was overexpressed in all of the cases. Aberrant nuclear staining for p53 was noted in all but one case. Increased intracellular accumulation of B-catenin was present in $50 \%$ of the cases. Three of the eight tumors had positive immunohistochemical staining for inhibin. Five of the eight tumors stained positively for SF-1, while two were negative, and one did not have adequate tissue available for staining. The results of immunohistochemical staining are summarized in Table 2.

Two of the eight patients had tumors with sarcomatoid features. Interestingly, lack of SF-1, inhibin, and aberrant B-catenin expression was noted in the sarcomatoid regions of these tumors.

\section{Clinical review}

Seven of the eight patients had surgical resection. One patient presented with metastatic disease identified as ACC on lung biopsy. The median length of follow-up was 8 months (range 0.8 to 60.2). The most common presentation was an incidentally discovered mass during imaging (six of eight patients). One patient was presented with Cushing's syndrome, and one was presented with symptoms related to metastatic lung disease. Three patients experienced recurrence, 2.3 to 6.5 months after resection. Of the four patients who died, three died with metastatic ACC and one died due to other medical comorbidities without ever having identified disease recurrence. The clinical data for all of the patients are summarized in Table 3.

\section{Sarcomatoid cases}

Case 3 in Tables 2 and 3 is a 65-year-old male who, during work-up for claudication, was found incidentally to have a large adrenal mass as well as a renal mass. He had an open radical nephrectomy. The suprarenal tumor measured $12.8 \times 8.9 \times 7.5 \mathrm{~cm}$. Microscopically, the suprarenal tumor was composed of solid sheets of epithelioid cells with abundant eosinophilic cytoplasm and spindled cells, which in some areas formed a fascicular growth pattern as seen in Figure 1. There was marked nuclear pleomorphism including occasional malignant multinucleated giant cells. There was no heterologous differentiation although a few cells had eosinophilic rhabdoid-like globules. Both typical and atypical mitoses were identified with an average of 20 mitoses per $20 \mathrm{HPF}$ as seen in Figure 1b. Based on WHO recommendations, this tumor with a spindled morphology qualified for being a sarcomatoid variant [7].This patient remains disease-free at 4 months.

Case 7 in Tables 2 and 3 is a 68-year-old lady who was incidentally found to have a large adrenal tumor during follow-up imaging for a previous lung adenocarcinoma. She had a radical nephrectomy. The adrenal tumor measured $13.0 \times 11.0 \times 9.0 \mathrm{~cm}$. Microscopically, much of the tumor was hemorrhagic and necrotic. The neoplasm showed marked pleomorphism with frequent multinucleated giant cells as seen in Figure 2a. There were epithelioid areas and sarcomatoid areas with spindled cells in a myxomatous background as seen in Figure $2 \mathrm{~b}$. There were numerous typical mitoses, five per single HPF in some areas, and atypical mitoses. In agreement with WHO recommendations, this is a sarcomatoid carcinoma [7]. This patient had disease recurrence invading the gastroduodenal artery within 68 days. She required multiple transfusions and embolization of the artery for control of bleeding. She succumbed to her disease 223 days after initial surgery.

\section{Discussion}

\section{Epidemiology and clinical presentation}

Adrenocortical carcinoma is a rare malignancy with an annual incidence of 0.5 to 2.0 per million people with a female-to-male ratio of 1.2 to 1.5:1 [1-4]. The average age of presentation reported by Bilimoria et al. $(n=3,982)$ and Kutikov et al. $(n=4275)$ in the United States National

Table 2 Results of immunohistochemical staining for eight patients with adrenocortical carcinoma

\begin{tabular}{|c|c|c|c|c|c|c|c|}
\hline Case number & Age & Sex & Ki-67 (\%) & B-catenin intracellular accumulation & P53 (\%) & Inhibin & SF-1 \\
\hline 1 & 59 & M & 80 & Present & 85 & Positive & Positive \\
\hline 2 & 25 & $\mathrm{~F}$ & 40 & Present & 30 & Negative & Positive \\
\hline 3 & 65 & M & 20 & Absent & 30 & Negative & Negative \\
\hline 4 & 66 & $\mathrm{~F}$ & 50 & Absent & Focal & Positive & Tissue not available \\
\hline 5 & 79 & $M$ & 10 & Present & 10 & Positive & Positive \\
\hline 6 & 34 & $\mathrm{~F}$ & 85 & Present & 90 & Negative & Positive \\
\hline 7 & 68 & $\mathrm{~F}$ & 60 & Absent & 60 & Negative & Negative \\
\hline 8 & 32 & $\mathrm{~F}$ & 10 & Absent & Absent & Negative & Positive \\
\hline
\end{tabular}

F, female; M, male; SF-1, steroidogenic factor-1. 
Table 3 Clinical data for eight patients with adrenocortical carcinoma

\begin{tabular}{|c|c|c|c|c|c|}
\hline Case number & Age & Sex & Presentation & Time to recurrence (days) & Time to death (days) \\
\hline 1 & 59 & M & Cushingoid & N/A & N/A \\
\hline 2 & 25 & $\mathrm{~F}$ & Incidentally & 119 & N/A \\
\hline 3 & 65 & M & Incidentally & N/A & N/A \\
\hline 4 & 66 & $\mathrm{~F}$ & Metastatic & 0 & 25 \\
\hline 5 & 79 & M & Incidentally & N/A & 353 \\
\hline 6 & 34 & $\mathrm{~F}$ & Incidentally & 195 & 254 \\
\hline 7 & 68 & $\mathrm{~F}$ & Incidentally & 68 & 223 \\
\hline 8 & 32 & $\mathrm{~F}$ & Incidentally & $\mathrm{N} / \mathrm{A}$ & $\mathrm{N} / \mathrm{A}$ \\
\hline
\end{tabular}

F, female; $M$, male; N/A, not available.

Cancer Data Base is 55 years [1,4]. This is similar to the average age in our case series of 53.5 years. The demographic information from the five largest published case series ( $n>300$, from unique databases) on ACC, is tabulated in Table 4 [1-4,8-14].

Cases series with data from identical databases were not included. In this manuscript, we have elected to tabulate publications with the largest $n$ from their independent databases. In this context, the following studies that are not represented are as follows: Bilimoria et al. (National Cancer Database, $n=3,982$ ) [1], Lughezzani et al. (SEER, $n=573)$ [11], Sturgeon et al. (SEER, $n=457)$ [12], Johanssen et al. (German ACC Registry, $n=387$ ) [13], and Tran et al. (SEER, $n=320$ ) [14]. ACC, adrenocortical carcinoma.

Pediatric ACCs have several important differences compared to adult ACCs. The incidence in children is much lower with only 25 new cases of ACC being diagnosed in the USA every year [15]. The incidence for children is greatest in the first year of life [16]. ACC is more common than adrenocortical adenoma in children (approximately 3:1 in newborns and 2:1 in older children) $[17,18]$. The clinical presentation of these tumors in children is also different with more pediatric patients presenting with symptoms of adrenal hormone hypersecretion. The most common presentation in children is virilization, followed by Cushing's syndrome [19]. In fetal and newborn patients, the main presentation was an abdominal mass found on physical examination or antenatal sonography, but this is followed closely by virilization [18]. However, pathological diagnosis of pediatric ACC is more challenging because frequently used adult histopathological criteria, such as the Weiss criteria, have not been shown to accurately predict tumor behavior in children and therefore their use is not recommended. Instead, adrenocortical tumors in children should be classified as clinically benign or clinically malignant based on their clinical course [15]. Outcomes in children are better than in adults, with a reported 5-year overall survival of $57 \%$, which is even higher $(91.1 \%)$ in patients under the age of 5 [16].

Clinical presentation of ACC is variable. While most ACCs are biochemically functional, in many patients this does not manifest clinically, and a large proportion of tumors are discovered incidentally or are metastatic at the time of presentation [20-22], with the most common sites of distant metastasis being, in decreasing frequency, the liver, lungs, and bone [1]. In our series, six out of eight patients presented with incidentally discovered tumors, and only one patient had metastatic disease on presentation. One patient presented with Cushing's syndrome. The reported proportion of functioning ACC varies in the

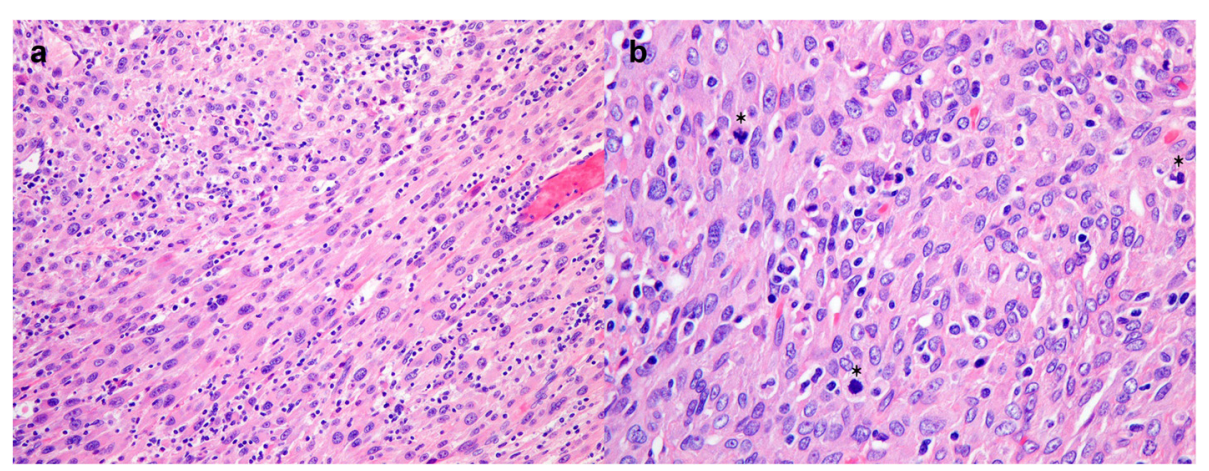

Figure 1 Photomicrograph showing (a) epithelioid spindled cells with abundant eosinophilic cytoplasm in a fascicular pattern and (b) increased mitotic activity $(*)$ with typical and atypical mitoses. 


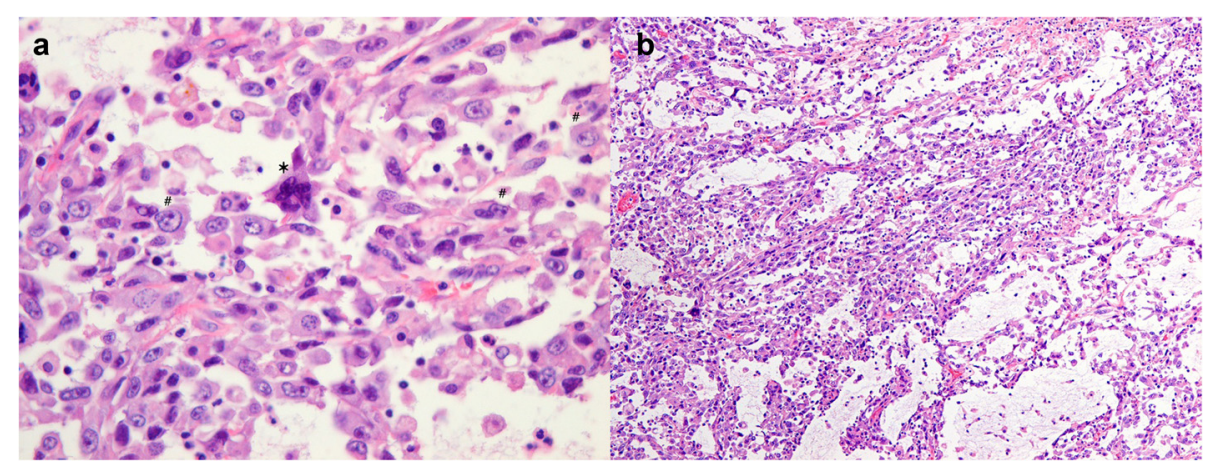

Figure 2 Photomicrograph showing (a) malignant cells with marked nuclear pleomorphism (\#) and the presence of a multinucleated tumor giant cell $\left(^{*}\right)$ and (b) sarcomatoid areas with spindled cells in a myxomatous background.

literature, but the majority is functioning, and most functional tumors secrete cortisol [20-22].

\section{Diagnosis \\ Imaging}

While imaging is not able to definitively diagnose malignancy in an adrenal mass, modern modalities can correctly differentiate adrenal masses before histopathological diagnosis in most cases. The most obvious characteristic noted on cross-sectional imaging of an adrenal mass is the size of the lesion. A cut-off of $4 \mathrm{~cm}$ has a sensitivity of 93\% for identifying adrenal carcinoma and, while this is a conservative size cut-off, it should be used due to the aggressive nature of ACC and the importance of early diagnosis [5]. Higher cut-offs of 5 or $6 \mathrm{~cm}$ have been suggested with sensitivities of $90 \%$ or greater in smaller studies [23,24]. Beyond size, few other features of the mass on unenhanced and contrast-enhanced CT help to steer accurate radiographic identification. The density of the adrenal lesion has been proposed as a valuable tool, and benign adenomas tend to be more lipid-rich and have Hounsfield unit densities less than 10 [23,25]. Tumor extension into the IVC with a tumor thrombus is seen in a proportion of tumors, particularly in rightsided tumors, and is indicative of malignancy. On contrast-enhanced CT, little enhancement is seen in the central necrosis of malignant tumors compared to the peripheral tumor [24,25]. Lastly, on contrastenhanced imaging, the relative percentage of contrast agent enhancement washout seen in malignant tumors after 15 min is generally less than 40\% [24-26]. Abdominal $\mathrm{CT}$ can be combined with chest imaging in order to establish the presence of any metastatic lung disease. The efficacy of MRI is relatively equivalent to that of CT and in patients where radiation is not a concern, CT scan is recommended as the initial radiographic modality [21,23].

Since not all patients with functioning tumors present with symptoms of hormonal excess, a careful endocrine work-up should be performed and the absence of secretion should alert clinicians to the possibility that the mass is not an ACC [20,21]. In contrast, adrenal adenomas are less likely to be functioning and are generally significantly smaller than adrenal carcinomas when discovered incidentally [5].

Biopsy of adrenal masses has a low diagnostic accuracy and may promote needle track metastases. As such, biopsy is not suggested as part of the diagnostic work-up except in patients with metastatic disease, not scheduled for surgery, in whom the diagnosis remains unestablished or in patients with a suspicious endocrine-inactive adrenal mass and a history of an extra-adrenal malignancy [21]. In patients who do not meet these conditions, biopsy of the adrenal mass unnecessarily delays the diagnosis of malignancy.

\section{Histopathology}

Three histopathological scoring systems for distinguishing benign from malignant ACCs have been proposed. The Hough system employs 12 criteria, 7 histologic and 5 nonhistologic. Each criterion is assigned a numeric value, and the total score is predictive of the biologic behavior of the tumor [27]. The Hough criteria are tabulated in Table 5. Slooten et al. have also proposed a scoring system [28]. Their system includes seven histological criteria and no non-histological criteria. In contrast to the Hough system, the Slooten criteria are not limited by the availability of clinical findings. The Slooten system also assigns numeric values to its criteria and a total value greater than eight is correlated with tumor behavior [27]. The Slooten criteria are tabulated in Table 6.

The Weiss criteria introduced in 1984 [29], later revised [30], and then modified in 2002 [31], are the current standard of practice to establish the diagnosis of ACC. Histopathological diagnosis of ACC is made when tumors meet three of the nine Weiss criteria as listed below [21,30,32]: 1 ) grade 3 or 4 nuclear grade (enlarged, oval to lobulated nuclei with coarsely granular to hyperchromatic chromatin and easily discernible, prominent nucleoli); 2) 
Table 4 Largest ACC case series published to date $(n>300)$

\begin{tabular}{|c|c|c|c|c|c|c|c|c|}
\hline Reference & $\begin{array}{l}\text { Published } \\
\text { year }\end{array}$ & Country & Database & $\begin{array}{l}\text { Number of } \\
\text { patients }\end{array}$ & $\begin{array}{l}\text { Average } \\
\text { Age (years) }\end{array}$ & $\begin{array}{l}\text { Male-to-female } \\
\text { ratio }\end{array}$ & $\begin{array}{l}\text { Median tumor } \\
\text { size }(\mathrm{cm})\end{array}$ & $\begin{array}{l}\text { Proportion of tumors with } \\
\text { distant metastasis at } \\
\text { presentation (\%) }\end{array}$ \\
\hline Kutikov et al. [4] & 2011 & United States & National Cancer Database & 4,275 & 54.5 & $41.9 \%$ to $58.1 \%$ & 11.5 & 34.4 \\
\hline Kebebew et al. [3] & 2006 & United States & $\begin{array}{l}\text { Surveillance, Epidemiology, and End Results } \\
\text { (SEER) Database }\end{array}$ & 725 & 51.2 & $45.9 \%$ to $54.1 \%$ & 12 & 34.8 \\
\hline Fassnacht et al. [8] & 2009 & Germany & The German ACC Registry & 416 & 46.7 & $37.3 \%$ to $62.7 \%$ & 11.3 & 29.3 \\
\hline Else et al. [9] & 2014 & United States & Michigan Endocrine Oncology Repository & 391 & 47.4 & $40 \%$ to $60 \%$ & 11.8 & 29 \\
\hline Kerkhofs et al. [2] & 2013 & Netherlands & Netherlands Cancer Registry & 359 & 56 & $45 \%$ to $55 \%$ & Not available & 35 \\
\hline Ayala-Ramirez et al. [10] & 2013 & United States & $\begin{array}{l}\text { Tumor Registry Database at the University of } \\
\text { Texas MD Anderson Cancer Center }\end{array}$ & 330 & 48.5 & $35.8 \%$ to $64.2 \%$ & $11 \mathrm{~cm}$ & 25.8 \\
\hline
\end{tabular}


Table 5 Hough system criteria

\begin{tabular}{ll}
\hline Criteria & Numeric value \\
\hline Histological & 0.92 \\
Diffuse growth pattern & 0.92 \\
Vascular invasion & 0.69 \\
Tumor cell necrosis & 1.00 \\
Broad fibrous bands & 0.37 \\
Capsular invasion & 0.60 \\
Mitotic index (>1/10 HPFs) & 0.39 \\
Pleomorphism & \\
Nonhistologic & 0.60 \\
Tumor mass (>100 g) & 0.50 \\
Urinary 17-ketosteroids (10 mg/1 g creatinine 24 h) \\
$\begin{array}{ll}\text { Response to ACTH (17-hydroxysteroids increased two } \\
\text { times after } 50 \text { mcg of IV ACTH) }\end{array}$ \\
$\begin{array}{ll}\text { Cushing syndrome with virilism, virilism alone, or no } \\
\text { Clinical manifestations }\end{array}$ & 0.42 \\
Weight loss (>10 Ib/3 months) & \\
\hline
\end{tabular}

ACTH, adrenocorticotropic hormone; HPFs, high-powered fields.

mitotic grade $>5 / 50$ HPFs; 3) atypical mitoses; 4) clear cells comprising $25 \%$ or less of the tumor; 5 ) diffuse architecture greater than one third of the tumor; 6) necrosis; 7) invasion of venous structures; 8 ) invasion of sinusoidal structures; and 9) invasion of the tumor capsule.

To simplify the Weiss system, while retaining diagnostic value and improving interobserver reliability, a revised system was proposed by Aubert et al. [31]. Their system requires assessment of only five Weiss criteria: i) mitotic grade, ii) percent of clear cells comprising the tumor, iii) abnormal mitoses, iv) necrosis, and v) capsular invasion. Though the total Weiss score has been shown to have high interobserver agreement [31], the interobserver reliability of individual criteria has been criticized $[27,33]$. In particular, nuclear grade, proportion of clear cells, and architectural assessment may have high variability among different observers. Recently, the reticulin method simplifies the Weiss system. This method requires histochemical staining for reticulin with microscopic examination of the

Table 6 van Slooten criteria

\begin{tabular}{ll}
\hline Criteria & Numeric value \\
\hline Regressive changes such as necrosis, hemorrhage, & 5.7 \\
fibrosis, or calcification & 1.6 \\
Loss of normal structure & 2.1 \\
Nuclear atypia & 2.6 \\
Nuclear hyperchromasia & 4.1 \\
Abnormal nucleoli structure & 9.0 \\
Mitotic activity >2/10 HPFs & 3.3 \\
Capsular or vascular invasion &
\end{tabular}

HPFs, high-powered fields. reticulin/basal membrane network. Any tumor with a disrupted reticulin framework as well as the presence of mitosis $>5 / 50 \mathrm{HPFs}$, necrosis, or venous invasion meets the algorithm's criteria and is considered malignant [34]. This most recent algorithm has been validated and is shown to have relatively high interobserver agreement [33], albeit lower than reported for the total Weiss score [31]. In light of this finding, we stained specimens in our study for reticulin and seven of the eight tumors had a disrupted reticulin framework. On blinded review, the tumor which had an intact reticulin framework (case 5) also lacked Weiss criteria on examination by the study pathologist. Having been initially reported as having diffuse necrosis, $>5$ mitotic figures per $50 \mathrm{HPFs}$, and capsular invasion, these histological features were not seen on re-examination of select slides. Furthermore, the tumor weighed only $46 \mathrm{~g}$ $(4.7 \mathrm{~cm})$. Therefore, whether this tumor truly represents an adrenal carcinoma remains debatable. Unfortunately, clinical correlation was impossible in this patient because they died of unrelated causes within 1 year of initial diagnosis. An incorrect initial diagnosis is not uncommon in adrenocortical carcinoma. A large audit of cases in Germany identified a high histopathological misclassification rate of $13 \%$ [13].

\section{Immunohistochemistry}

TP53 The TP53 tumor suppressor gene, linked with La-Fraumeni syndrome, is frequently mutated in cancers, including adrenocortical carcinoma. In Southern Brazil, the incidence of adrenocortical tumors is unusually high, coinciding with a high prevalence of the germ line TP53 mutation $\mathrm{R} 337 \mathrm{H}$ which is present in up to $0.5 \%$ of newborns in specific regions of Southern Brazil [35]. Carriers of this particular mutation have been found to have a penetrance of $2.39 \%$ to $9.9 \%$ for adrenocortical tumors [35,36], with most tumors being carcinomas [35]. Interestingly, this particular TP53 mutation was not found to predispose to extra-adrenal cancers, although this relationship was not studied rigorously [36]. In Caucasian patients with ACC, TP53 germ line mutation analysis has revealed a frequency of $3.9 \%$ in adult patients which suggests a specific role for TP53 in ACC tumorigenesis [37]. Loss of heterozygosity of $17 \mathrm{p} 13$, on which TP53 is encoded, is studied as a valuable diagnostic marker. In one series, $74 \%$ of ACCs, compared with $14 \%$ of adenomas, had loss of heterozygosity at 17p13 [38]. Gicquel et al. also noted the value of $17 \mathrm{p} 13$ loss of heterozygosity as an independent predictor of disease-free survival [39].

Immunohistochemical staining for p53 expression in ACC has found aberrant nuclear staining in a varying proportion of carcinomas, $5 \%$ to $60 \%$ [40-42]. As such, use of p53 expression to help distinguish benign from malignant adrenal tumors may be an important adjuvant 
to the current histopathological criteria. This is particularly true since aberrant expression is extremely rare in adenomas [41-43]. Patients with increased p53 staining tend to have higher grade tumors, reflected by higher Ki-67 expression, higher tumor stage, and poorer disease-free survival [44]. However, p53 has not been shown to be related to overall survival [44], and its correlation with poor clinical outcomes is likely due to its association with higher tumor grade. In our series, five of the eight tumors had $>10 \%$ cells with aberrant expression of p53, and the two cases with highest aberrant p53 expression $(>85 \%)$ also had the highest proliferative activity (Ki-67 > 80\%).

SF-1 SF-1 expression is specific to the adrenal cortex [45]. It plays an important role in adrenal development and remains expressed into adulthood [46]. Consequently, adrenal tumorigenesis is influenced by the proliferative effect of SF-1, and SF-1 overexpression has been shown in tumors originating from the adrenal cortex [45,47]. In particular, this has been noted in childhood adrenal tumors where an increased copy of the SF1 gene is associated with tumorigenesis $[48,49]$.

SF-1 immunohistochemical staining has particular clinical value because its expression has high sensitivity and specificity in determining adrenocortical origin of an adrenal mass [45]. As such, it should be used to differentiate adrenal masses [21]. Interestingly, SF-1 has been found to have independent prognostic value in multivariate analysis. Strong SF-1 expression is associated with poor clinical outcome in ACC even after adjustment for stage $[45,47]$. In the future, the utility of SF-1 may extend to treatment. Inverse agonists of SF-1 have been studied in vitro on human ACC cells with success and may have some clinical utility, although this is yet to be trialed [50].

Five out of eight of our cases stained positively for SF-1. Interestingly, case 3 and 7, which were histologically sarcomatoid, did not stain for SF-1 in the sarcomatoid areas of the tumors. This is shown in Figure 3a,b. Given the role of SF-1 in adrenocortical cellular development, the lack of SF-1 staining in sarcomatoid adrenal tumors suggests an alternative pathway of development for these tumors. These findings suggest that sarcomatoid adrenocortical carcinoma may arise from a de novo rather than a dedifferentiation mechanism. SF-1 staining was unfortunately not performed in other published cases of sarcomatoid ACC. This finding needs to be confirmed in the future, potentially in a meta-analysis of published sarcomatoid ACC cases with SF-1 staining.

B-catenin Wnt/B-catenin signaling is thought to be integral to adrenal gland cellular growth and regulation [51]. Activation of this pathway has been shown to be an important factor in tumorigenesis in both benign and malignant tumors of the adrenal cortex [21,51,52]. B-catenin is normally found on the plasma membrane, associated with E-cadherins, or in the cytoplasm and nucleus where its accumulation influences the Wnt signaling pathway. When accumulation is abnormally increased due to activating mutations, there is abnormal Wnt pathway activation resulting in tumor formation [51]. This has been demonstrated in a mouse model, where constitutive activation of B-catenin in the adrenal glands has been shown to induce adrenocortical cell hyperproliferation and loss of differentiation [53]. In the older mice, this process resulted in malignant transformation [53].

Immunohistochemical staining for B-catenin can identify abnormal activation, demonstrated as cytoplasmic or nuclear staining. Both adenomas and carcinomas have been shown to have abnormal B-catenin staining, with more diffuse and frequent immunostaining in malignant tumors [54]. Abnormal B-catenin staining has been associated with high-grade ACC, correlating with both high mitotic rate [55] and poor prognosis [56,57]. However, in multi-variate analysis, when the effects of tumor grade are considered, B-catenin has not been shown to have independent prognostic value [55]. In our series,

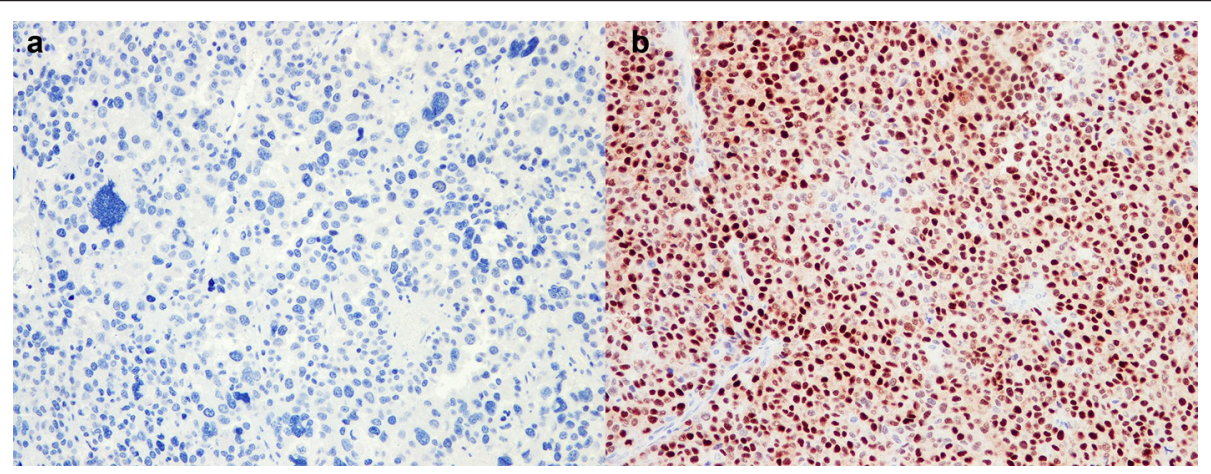

Figure 3 Photomicrograph of SF-1 stained slide showing (a) adrenocortical carcinoma demonstrating positive staining for SF-1 and (b) sarcomatoid region of adrenocortical carcinoma with absent staining for SF-1. 
cytoplasmic staining for B-catenin was found in 50\% of the tumors, including tumors with increased coexpression of $\mathrm{Ki}-67$.

Inhibin Adrenal inhibins have been shown to stain specifically to the adrenal cortex, and particularly to the zona reticularis, with weaker staining in the zona fasciculata and no staining in the zona glomerulosa [58]. Thus, immunohistochemical staining for adrenal inhibin expression is useful to distinguish tumors of adrenal origin. In an early study, Fetsch et al. demonstrated immunoreactivity to an adrenal inhibin antibody in all adrenocortical carcinomas and adenomas [59]. However, later studies revealed that a proportion of adrenal tumors are immunonegative, and that negative staining does not exclude the diagnosis of ACC $[58,60]$. High expression of adrenal inhibin is seen particularly in virilising tumors [58]. Unfortunately, immunopositivity to adrenal inhibin antibodies does not help distinguish benign from malignant adrenal tumors $[58,60]$. In our series, only three of eight tumors stained positively for adrenal inhibin.

IGF Genetic alterations at the 11p15 chromosomal locus result in an overexpression of IGF-2 in adrenal cortex cells and are fairly specific to both sporadic and syndromic adrenocortical carcinomas but not adenomas $[43,52,55,61]$. Signaling of IGF-2 through its receptor IGF-1R is thought to play an important role in ACC tumorigenesis [61]; however, recent in vivo experiments have demonstrated that isolated over expression of IGF2, while specific for malignant cells, is not a driving factor in ACC malignant progression [52]. Nonetheless, IGF-2 and IGF-1R antagonists are considered targets for drug development. IGF-1R antagonists have been tested in vitro with promising results on human ACC cells $[62,63]$. Unfortunately, there has been little success with IGF antagonists in-vivo [52,64].

\section{Pathogenesis}

Syndromal ACC ACC, particularly in children, is often associated with familial syndromes $[65,66]$. La-Fraumeni syndrome, associated with germ line mutations in the TP53 gene, is present in the majority of children with adrenocortical tumors but is seen less commonly in adults $[37,65]$. Patients with Beckwith-Wiedemann syndrome have overexpression of IGF-2 due to loss of the maternal locus, $11 \mathrm{p} 15$ [66]. This mutation is associated with tumors exclusive to childhood and frequently results in benign, and rarely malignant, adrenal tumors [65]. Although the majority of adult ACC has been thought to be sporadic, there is growing evidence of the co-existing presence of hereditary cancer syndromes such as Lynch syndrome [67], multiple endocrine neoplasia type 1 [68], and familial adenomatous polyposis syndrome [56].

\section{Staging and prognosis}

Identification of tumor features which stratify patients into high and low risk groups is of upmost clinical importance. The most obvious is tumor stage which can be characterized by either the older International Union Against Cancer system or the newer European Network for the Study of Adrenal Tumors (ENS@T) system. The ENS@T system has demonstrated better prognostic stratification and is currently more widely used. It is summarized as follows with corresponding 5-year disease-specific survivals $[8,11]$ :

Stage I - tumor size less than or equal to $5 \mathrm{~cm} ; 82 \%$. Stage II - tumor size greater than $5 \mathrm{~cm} ; 58 \%$.

Stage III - any tumor size with at least one positive lymph node or tumor infiltrating into surrounding adipose tissue or adjacent organs including the presence of venous tumor thrombus in the inferior vena cava or renal vein; $55 \%$.

Stage IV - any metastatic disease; $18 \%$.

Further stratifying prognosis beyond disease stage is an important area of ACC research. Weiss first noted the importance of mitotic figures as one of the most useful criteria in distinguishing benign from malignant tumors [29], and Volante et al. further suggested stratifying patients into prognostic groups based on mitotic grade with a cutoff of 9 per 50 HPF indicating a high risk tumor [34]. In metastatic ACC, a higher mitotic rate cutoff of 20 per $50 \mathrm{HPF}$ has been shown to be useful in predicting poor outcome [69]. Recently, immunohistochemical analysis of the cellular proliferation marker Ki-67 has been recognized as a more reliable method than the mitotic index in diagnosing ACC and stratifying prognosis [21,70,71]. Few other tumor features have been identified as having possible prognostic importance. One might expect that functioning tumors may have better prognosis due to clinical cues and earlier diagnosis, however, in addition to higher patient age at diagnosis, functional tumors are independently associated with poorer survival $[10,20,72]$. In metastatic ACC, involvement of fewer tumoral organs is a predictor of better disease-specific survival [69]. As discussed previously, loss of heterozygosity at $17 \mathrm{p} 13$ and SF-1 protein staining have been shown to be stage-independent prognostic factors, while p53 and B-catenin staining have not. As such, there are relatively few useful independent prognostic markers for ACC and a nomogram using only three variables (age, stage, and surgical status) achieved up to $80 \%$ accuracy for survival prediction in a large cohort $(n=205)$ of patients [73]. 


\begin{tabular}{|c|c|c|c|c|c|c|c|c|}
\hline Reference & Age & Sex & Clinical presentation & Laterality & Size & Treatment & Time to recurrence & Time to death \\
\hline Okazumi et al. [74] & 46 & M & Abdominal distention + back pain & Right & $14 \mathrm{~cm}$ & $\begin{array}{l}\text { Right adrenalectomy and nephrectomy } \\
\text { followed by removal of the tumor } \\
\text { thrombus }\end{array}$ & 5 months & 206 days \\
\hline Collina et al. [75] & 68 & $\mathrm{~F}$ & Abdominal discomfort & Right & $11 \mathrm{~cm}$ & $\begin{array}{l}\text { Surgical resection followed by radiotherapy } \\
\text { after tumor recurrence }\end{array}$ & 2 months & 6 months \\
\hline Decorato et al. [76] & 42 & $\mathrm{~F}$ & Abdominal pain & Left & $19 \mathrm{~cm}$ & Surgical resection & 3 months & 7 months \\
\hline Fischler et al. [77] & 29 & $\mathrm{~F}$ & Virilization & Left & $12.5 \mathrm{~cm}$ & $\begin{array}{l}\text { Nephroadrenalectomy and splenectomy } \\
\text { followed by systemic chemotherapy } \\
\text { (cisplatin and etoposide) after recurrence }\end{array}$ & 4 months & 8 months \\
\hline Barksdale et al. [78] & 79 & $\mathrm{~F}$ & Severe hypertension & Right & $9 \mathrm{~cm}$ & Right adrenalectomy and cavotomy & 4 months & Not reported \\
\hline Lee et al. [79] & 61 & M & Flank pain + hypertension & Right & $12 \mathrm{~cm}$ & $\begin{array}{l}\text { Radical nephrectomy and right hepatic } \\
\text { lobectomy }\end{array}$ & No recurrence noted & 2 days \\
\hline Sturm et al. [7] & 31 & M & Abdominal pain & Left & $12 \mathrm{~cm}$ & $\begin{array}{l}\text { Adrenalectomy followed by systemic } \\
\text { chemotherapy (VP16-cisplatinum) after } \\
\text { recurrence }\end{array}$ & 2 months & 3 months \\
\hline Coli et al. (2009) [80] & 75 & $\mathrm{~F}$ & Abdominal pain & Left & $15 \mathrm{~cm}$ & Adrenalectomy and splenectomy & 3 months & 12 months \\
\hline Feng et al. [81] & 72 & M & Left lumbar pain & Left & $\begin{array}{l}7.1 \mathrm{~cm} \text { on } \\
C T \text { scan }\end{array}$ & Surgical resection & Not reported & Not reported \\
\hline Sasaki et al. [82] & 45 & M & $\begin{array}{l}\text { Abdominal pain, fever, nausea, } \\
\text { vomiting, anorexia, hypertension }\end{array}$ & Left & $17 \mathrm{~cm}$ & $\begin{array}{l}\text { Radical nephrectomy, splenectomy, distal } \\
\text { pancreatectomy, left partial colectomy, and } \\
\text { wedge biopsy of one hepatic lesion }\end{array}$ & $\begin{array}{l}\text { Hepatic metastasis at } \\
\text { presentation. Locoregional } \\
\text { recurrence at } 3 \text { months }\end{array}$ & 3 months \\
\hline Bertolini et al. [83] & 23 & $\mathrm{~F}$ & $\begin{array}{l}\text { Incidentally during work-up of meta- } \\
\text { static rectal mass }\end{array}$ & Left & $14 \mathrm{~cm}$ & $\begin{array}{l}\text { Left adrenalectomy with systemic } \\
\text { chemotherapy for metastatic rectal cancer }\end{array}$ & $\begin{array}{l}\text { Not reported, however patient } \\
\text { had metastatic lesions on } \\
\text { presentation which were } \\
\text { presumed to be rectal cancer } \\
\text { based on the co-existence of a } \\
\text { metastatic rectal cancer lesion } \\
\text { in the adrenal gland }\end{array}$ & 14 months \\
\hline Thway et al. [84] & 45 & M & Abdominal bloating + back pain & Left & $24 \mathrm{~cm}$ & $\begin{array}{l}\text { Left radical nephrectomy and splenectomy } \\
\text { followed by palliative chemotherapy } \\
\text { (vincristine, ifosfamide, carboplatin, } \\
\text { doxorubicin, and etoposide) }\end{array}$ & Metastatic at presentation & 11 months \\
\hline Yan et al. [85] & 72 & M & Flank pain & Right & $13 \mathrm{~cm}$ & Adrenalectomy & 2 years & 2.5 years \\
\hline Kao et al. [86] & 48 & $\mathrm{~F}$ & $\begin{array}{l}\text { Abdominal pain + hypokalemia + } \\
\text { weight loss }\end{array}$ & Right & $15 \mathrm{~cm}$ & $\begin{array}{l}\text { Adrenalectomy, partial nephrectomy, and } \\
\text { partial hepatectomy followed by systemic } \\
\text { chemotherapy (cisplatin and ifosfamide) } \\
\text { after distant metastasis }\end{array}$ & 2 months & $\begin{array}{l}\text { Alive with disease at } \\
7 \text { month follow-up }\end{array}$ \\
\hline Mark et al. [87] & 58 & M & Flank pain & Right & $12 \mathrm{~cm}$ & $\begin{array}{l}\text { Radial nephrectomy followed by eternal } \\
\text { beam radiotherapy to the tumor site }\end{array}$ & $\begin{array}{l}\text { Not reported after } 16 \text { month } \\
\text { follow-up }\end{array}$ & $\begin{array}{l}\text { Not reported after } \\
16 \text { month follow-up }\end{array}$ \\
\hline Shaikh et al. [88] & 62 & $\mathrm{~F}$ & Abdominal pain & Right & $6.5 \mathrm{~cm}$ & Adrenalectomy & 3 months & 4 months \\
\hline
\end{tabular}




\section{Conclusions}

Despite significant advancement in the past 15 years, accurate diagnosis of ACC remains challenging. The Weiss criteria remain the gold standard for histopathological diagnosis, but lack of interobserver reliability in their assessment has led to the emergence of newer techniques such as the reticulin method. Even in our case series, the challenge of ACC diagnosis is demonstrated. We identified one patient where the initial diagnosis of ACC may have been incorrect on re-examination of histopathological and reticulin staining criteria (case 5). Immunohistochemistry is a growing area of research and several markers have been identified to have clinical value. SF-1 overexpression establishes the adrenal cortex as the origin of adrenal tumors, and the intensity of SF-1 staining is related to prognosis. Interestingly, in our series, sarcomatoid regions in cases 3 and 7 did not express SF-1. This raises the possibility of a de novo mechanism of pathogenesis for these rare and highly aggressive tumors. Accuracy in stratification of malignant adrenocortical tumors may be improved by staining for B-catenin and p53 which are more frequently expressed in ACC but have not been found to have independent prognostic value.

Our case series adds eight cases to the existing literature, with very high expression of p53 and B-catenin seen in the cases with the highest proliferative activity. Sarcomatoid ACC is extremely rare with very few cases reported in the literature, and these tumors are usually associated with a very poor patient outcome. The published cases, in the English literature, of sarcomatoid ACC are tabulated in Table 7 [7,74-88]. In summary, as adrenocortical carcinoma is a rare disease, we recommend future multicenter studies with appropriate sample sizes to further evaluate and identify reliable diagnostic and prognostic markers.

\section{Competing interests}

The authors declare that they have no competing interests.

\section{Authors' contributions}

KW performed the collection and analysis of the clinical data. KW wrote the initial draft of the manuscript. RK performed the blinded pathological review and supervised the project. Both authors were involved in the study concept and design, review of the literature, and manuscript editing. Both authors read and approved the final manuscript.

\section{Author details}

${ }^{1}$ College of Medicine, University of Saskatchewan, Saskatoon, Canada. ${ }^{2}$ Department of Pathology and Laboratory Medicine, University of Saskatchewan, Saskatoon, Canada. ${ }^{3}$ Royal University Hospital, Room 2868G-Wing, 103 Hospital Drive, Saskatoon, Saskatchewan S7N 0W8, Canada.

Received: 1 August 2014 Accepted: 28 February 2015

Published online: 24 March 2015

\section{References}

1. Bilimoria KY, Shen WT, Elaraj D, Bentrem DJ, Winchester DJ, Kebebew E, et al. Adrenocortical carcinoma in the United States: treatment utilization and prognostic factors. Cancer. 2008;113:3130-6.

2. Kerkhofs T, Verhoeven RHA, Van der Zwan JM, Dieleman J, Kerstens MN, Links TP, et al. Adrenocortical carcinoma: a population-based study on incidence and survival in the Netherlands since 1993. Eur J Cancer. 2013;49:2579-86.

3. Kebebew E, Reiff E, Duh Q, Clark OH, McMillan A. Extent of disease at presentation and outcome for adrenocortical carcinoma: have we made progress? World J Surg. 2006:30:672-8

4. Kutikov A, Mallin K, Canter D, Wong Y, Uzzo RG. Effects of increased cross-sectional imaging on the diagnosis and prognosis of adrenocortical carcinoma: analysis of the National Cancer Database. J Urol. 2011;186:805-10.

5. Mantero F, Terzolo M, Arnaldi G, Osella G, Masini AM, Ali A, et al. A survey on adrenal incidentaloma in Italy. J Clinical Endocrinol Metab. 2000;85:637-44

6. Kanthan $\mathrm{R}$, Senger J, Kanthan S. Three uncommon adrenal incidentalomas: a 13-year surgical pathology review. World J Surg Oncol. 2012;10:64.

7. Sturm N, Moulai N, Laverriere M, Chabre O, Descotes J, Brambilla E. Primary adrenocortical sarcomatoid carcinoma: case report and review of literature. Virchows Arch. 2008;452:215-9.

8. Fassnacht M, Johanssen S, Quinkley M, Bucsky P, Willenberg HS, Beuschlein $F$, et al. Limited prognostic value of the, international union against cancer staging classification for adrenocortical carcinoma. Cancer. 2004;2009(115):243-50.

9. Else T, Williams AR, Sabolch A, Jolly S, Miller BS, Hammer GD. Adjuvant therapies and patient and tumor characteristics associated with survival of adult patients with adrenocortical carcinoma. J Clin Endocrinol Metab. 2014;99:455-61.

10. Ayala-Ramirez M, Jasim S, Feng L, Ejaz S, Deniz F, Busaidy N, et al. Adrenocortical carcinoma: clinical outcomes and prognosis of 330 patients at a tertiary care center. Eur J Endocrinol. 2013;169:891-9.

11. Lughezzani $G$, Sun $M$, Perrotte $P$, Jeldres $C$, Alasker $A$, Isbarn $H$, et al. The European network for the study of adrenal tumors staging system is prognostically superior to the international union against cancer-staging system: a North American validation. Eur J Cancer. 2010;46:713-9.

12. Sturgeon C, Shen WT, Clark OH, Duh Q, Kebebew E. Risk assessment in 457 adrenal cortical carcinomas: how much does tumor size predict the likelihood of malignancy? J Am Coll Surg. 2006;202:423-30.

13. Johanssen S, Hahner S, Saeger W, Quinkler M, Beuschlein F, Bralle H, et al. Deficits in the management of patients with adrenocortical carcinoma in Germany. Dtsch Arztebl Int. 2010;107:885-91.

14. Tran TB, Liou D, Menon VG, Nissen NN. Surgical management of advanced adrenocortical carcinoma: a 21-year population-based analysis. Am Surg. 2013;79:1115-8.

15. Faria $\mathrm{AM}, \mathrm{Almeida} \mathrm{MQ}$. Differences in the molecular mechanisms of adrenocortical tumorigenesis between children and adults. Mol Cell Endocrinol. 2012;351:52-7.

16. McAteer JP, Huaco JA, Gow KW. Predictors of survival in pediatric adrenocortical carcinoma: a Surveillance, Epidemiology, and End Results (SEER) program study. J Pediatr Surg. 2013;48:1025-31.

17. Hanna AM, Pham TH, Askegard-Giesmann JR, Grams JM, Iqbal CW, Stavlo P, et al. Outcome of adrenocortical tumors in children. J Pediatr Surg. 2008;43:843-9.

18. Isaacs Jr H. Fetal and newborn adrenocortical tumors. Fetal Pediatr Pathol. 2010;29:99-107.

19. Michalkiewicz E, Sandrini R, Figueiredo B, Miranga ECM, Caran E, Oliveira-Filho AG, et al. Clinical and outcome characteristics of children with adrenocortical tumors: a report from the international pediatric adrenocortical tumor registry. J Clin Oncol. 2004;22:838-45.

20. Abiven G, Coste J, Groussin L, Anract P, Tissier F, Legmann P, et al. Clinical and biological features in the prognosis of adrenocortical cancer: poor outcome of cortisol-secreting tumors in a series of 202 consecutive patients. J Clin Endocrinol Metab. 2006;91:2650-5.

21. Fassnacht M, Kroiss M, Allolio B. Update in adrenocortical carcinoma. J Clin Endocrinol Metab. 2013;98:4551-64.

22. Icard P, Goudet P, Charpenay C, Andreassian B, Carnaille B, Chapuis Y, et al. Adrenocortical carcinomas: surgical trends and results of a 253-patient series from the French Association of Endocrine Surgeons study group. World J Surg. 2001;25:891-7.

23. Young Jr WF. Conventional imaging in adrenocortical carcinoma: update and perspectives. Horm Canc. 2011;2:341-7.

24. Zhang HM, Perrier ND, Grubbs EG, Sircar K, Ye ZX, Lee JE, et al. CT features and quantification of the characteristics of adrenocortical carcinomas on unenchanced and contrast-enhanced studies. Clin Radiol. 2012;67:38-46. 
25. Bharwani N, Rockall AG, Sahdev A, Gueorguiev M, Drake W, Grossman AB, et al. Adrenocortical carcinoma: the range of appearances on CT and MRI. AJR. 2011;196:706-14.

26. Slattery JMA, Blake MA, Kalra MK, Misdraji J, Sweeney AT, Copeland PM, et al. Adrenocortical carcinoma: contrast washout characteristics on CT. AJR. 2006;187:21-4.

27. Sasano H, Suzuki T, Moriya T. Discerning malignancy in resected adrenocortical neoplasms. Endocr Pathol. 2001;12:397-406.

28. Slooten H, Schaberg A, Smeenk D, Moolenaar AJ. Morphologic characteristics of benign and malignant adrenocortical tumors. Cancer. 1985;55:766-73.

29. Weiss LM. Comparative histologic study of 43 metastasizing and nonmetastasizing adrenocortical tumors. Am J Surg Pathol. 1984;8:163-9.

30. Weiss LM, Medeiros J, Vickery AL. Pathologic features of prognostic significance in adrenocortical carcinoma. Am J Surg Pathol. 1989;13:202-6.

31. Aubert S, Wacrenier A, Leroy X, Devos P, Carnaille B, Proye C, et al. Weiss system revisited: a clinicopathologic and immunohistochemical study of 49 adrenocortical tumors. Am J Surg Pathol. 2002;26:1612-9.

32. Lau SK, Weiss LM. The Weiss system for evaluating adrenocortical neoplasms: 25 years later. Hum Pathol. 2009:40:757-68.

33. Duregon E, Fassina A, Volante M, Nesi G, Santi R, Gatti G, et al. The reticulin algorithm for adrenocortical tumor diagnosis: a multicentric validation study on 245 unpublished cases. Am J Surg Pathol. 2013;37:1433-40

34. Volante $\mathrm{M}$, Bollito $\mathrm{E}$, Sperone $\mathrm{P}$, Tavaglione V, Daffara F, Porpiglia F, et al. Clinicopathological study of a series of 92 adrenocortical carcinomas: from a proposal of simplified diagnostic algorithm to prognostic stratification. Histopathology. 2009;55:535-43.

35. Custodio G, Parise GA, Filho NK, Komechen H, Sabbaga CC, Rosati R, et al. Impact of neonatal screening and surveillance for the TP53 R337H mutation on early detection of childhood adrenocortical tumors. J Clin Oncol. 2013:31:2619-27.

36. Figueiredo BC, Sandrini R, Zambetti GP, Pereira RM, Cheng C, Liu W, et al. Penetrance of adrenocortical tumours associated with the germline TP53 R337H mutation. J Med Genet. 2006;43:91-6.

37. Herrmann LJM, Heinze B, Fassnacht M, Willenberg HS, Quinkley M, Reisch N, et al. TP53 germline mutations in adult patients with adrenocortical carcinoma. J Clin Endocrinol Metab. 2012;97:e476-85.

38. Soon PSH, Libe R, Benn DE, Gill A, Shaw J, Sywak MS, et al. Loss of heterozygosity of 17p13, with possible involvement of ACADVL and ALOX15B, in the pathogenesis of adrenocortical tumors. Ann Surg. 2008;247:157-64.

39. Gicquel C, Bertagna X, Gaston V, Coste J, Louvel A, Baudin E, et al. Molecular markers and long-term recurrences in a large cohort of patients with sporadic adrenocortical tumors. Cancer Res. 2001;61:6762-7.

40. Stojadinovic A, Ghassein RA, Hoos A, Nissan A, Marshall D, Dudas M, et al. Adrenocortical carcinoma: clinical, morphologic, and molecular characterization. J Clin Oncol. 2002:20:941-50.

41. Arola J, Salmenkivi K, Liu J, Kahri Al, Heikkila P. P53 and Ki-67 in adrenocortical tumors. Endocr Res. 2000;26:861-5.

42. Reincke M, Karl M, Travis WH, Mastorakos G, Allolio B, Linehan HM, et al. p53 mutations in human adrenocortical neoplasms: immunohistochemical and molecular studies. J Clin Endocrinol Metab. 1994;78:790-4.

43. Schmitt A, Saremaslani P, Schmid S, Rousson V, Montani M, Schmid DM, et al. IGFII and MIB1 immunohistochemistry is helpful for the differentiation of benign from malignant adrenocortical tumors. Histopathology. 2006;46:298-307.

44. Waldmann J, Patsalis N, Fendrich V, Langer P, Saeger W, Chaloupka B, et al. Clinical impact of TP53 alterations in adrenocortical carcinomas. Langenbecks Arch Surg. 2012;397:209-16.

45. Sbiera S, Schmull S, Assie G, Voelker H, Kraus L, Beyer M, et al. High diagnostic and prognostic value of steroidogenic factor-1 expression in adrenal tumors. J Clin Endocrinol Metab. 2010;95:e161-71.

46. Lalli E. Adrenocortical development and cancer: focus on SF-1. J Mol Endocrinol. 2010;44:301-7.

47. Duregon E, Volante M, Giorcelli J, Terzolo M, Lalli E, Papotti M. Diagnostic and prognostic role of steroidogenic factor 1 in adrneocortical carcinoma: a validation study focusing on clinical and pathologic correlates. Hum Pathol. 2013;44:822-8

48. Figueiredo BC, Cavalli LR, Pianovski MAD, Lalli E, Sandrini R, Ribeiro RC, et al. Amplification of the steroidogenic factor 1 gene in childhood adrenocortical tumors. J Clin Endocrinol Metab. 2005;90:615-9.

49. Pianovski MAD, Cavalli LR, Figueiredo BC, Santos SCL, Doghman M, Ribeiro $\mathrm{RC}$, et al. SF-1 overexpression in childhood adrenocortical tumours. Eur Cancer. 2006:42:1040-3.
50. Doghman M, Cazareth J, Douguet D, Madoux F, Hodder P, Lalli E. Inhibition of adrenocortical carcinoma cell proliferation by steroidogenic factor-1 inverse agonists. J Clin Endocrinol Metab. 2009;94:2178-83.

51. Berthon A, Martinez A, Bertherat J, Val P. Wnt/B-catenin signalling in adrenal physiology and tumour development. Mol Cell Endocrinol. 2012;351:87-95.

52. Drelon C, Berthon A, Val P. Adrenocortical cancer and IGF2: is the game over or our experimental models limited? J Clin Endocrinol Metab. 2013;98:505-7.

53. Berthon A, Sahut-Barnola I, Lambert-Langlais S, de Joussineau C, DamonSoubeyrand C, Louiset $\mathrm{E}$, et al. Constitutive B-catenin activation induces adrenal hyperplasia and promotes adrenal cancer development. Hum Mol Gen. 2010;19:1561-76.

54. Tissier F, Cavard C, Groussin L, Perlemoine K, Fumey G, Hagnere A, et al. Mutations of B-catenin in adrenocortical tumors: activation of the Wnt signaling pathway is a frequent event in both benign and malignant adrenocortical tumors. Cancer Res. 2005;65:7622-7.

55. Heaton JH, Wood MA, Kim AC, Lima LO, Barlaskar FM, Almeida MQ, et al. Progression to adrenocortical tumorigenesis in mice and humans through insulin-like growth factor 2 and B-catenin. Am J Pathol. 2012;181:1017-33

56. Gaujoux S, Grabar S, Fassnacht M, Ragazzon B, Launay P, Libe R, et al. B-catenin activation is associated with specific clinical and pathologic characteristics and a poor outcome in adrenocortical carcinoma. Clin Cancer Res. 2010;17:328-36.

57. Ragazzon B, Libe R, Gaujoux S, Assie G, Fratticci A, Launay P, et al. Transcriptome analysis reveals that p53 and B-catenin alterations occur in a group of aggressive adrenocortical cancers. Cancer Res. 2010;70:8276-81.

58. Arola J, Liu J, Heikkila P, Ilvesmaki V, Salmenkivi K, Voutilainen $\mathrm{R}$, et al. Expression of inhibin a in adrenocortical tumours reflects the hormonal status of the neoplasm. J Endocinol. 2000;165:223-9.

59. Fetsch PA, Powers CN, Zakowski MF, Abati A. Anti-a-inhibin: marker of choice for the consistent distinction between adrenocortical carcinoma and renal cell carcinoma in fine-needle aspiration. Cancer (Cancer Cytopathol). 1999:87:168-72

60. Weissferdt A, Phan A, Suster S, Moran CA. Adrenocortical carcinoma: a comprehensive immunohistochemical study of 40 cases. Appl Immunohistochem Mol Morphol. 2014;22:24-30.

61. Ribeiro TC, Latronico AC. Insulin-like growth factor system on adrenocortical tumorigenesis. Mol Cell Endocrinol. 2012;351:96-100.

62. Barlaskar FM, Spalding AC, Heaton JH, Kuick R, Kim AC, Thomas DG, et al. Preclinical targeting of the type I insulin-like growth factor receptor in adrenocortical carcinoma. J Clin Endocrinol Metab. 2009:94:204-12.

63. Doghman M, Axelson M, Lalli E. Potent inhibitory effect of the cyclolignan picropodophyllin (PPP) on human adrenocortical carcinoma cells proliferation. Am J Cancer Res. 2011;1:356-61.

64. Haluska P, Worden F, Olmos D, Yin D, Schteingart D, Batzel GN, et al. Safety, tolerability, and pharmacokinetics of the anti-IGF-1R monoclonal antibody figitumumab in patients with refractory adrenocortical carcinoma. Cancer Chemother Pharmacol. 2010;65:765-73.

65. Else T. Association of adrenocortical carcinoma with familial cancer susceptibility syndromes. Mol Cell Endocrinol. 2012;351:66-70.

66. Jain M, Rechache N, Kebebew E. Molecular markers of adrenocortical tumors. J Surg Oncol. 2012;106:549-56.

67. Raymond VM, Everett JN, Furtado LV, Gustafson SL, Jungbluth CR, Gruber $\mathrm{SB}$, et al. Adrenocortical carcinoma is a lynch syndrome-associated cancer. J Clin Oncol. 2013;31:3012-8

68. Langer P, Cupisti K, Bartsch DK, Nies C, Goretzki PE, Rothmund M, et al. Adrenal involvement in multiple endocrine neoplasia type 1. World J Surg. 2002;26:891-6.

69. Assie G, Antoni G, Tissier G, Caillou B, Abiven G, Gicquel C, et al. Prognostic parameters of metastatic adrenocortical carcinoma. J Clin Endocrinol Metab. 2007:92:148-54.

70. Terzolo M, Boccuzzi A, Bovio S, Cappia S, de Giuli P, Ali A, et al. Immunohistochemical assessment of Ki-67 in the differential diagnosis of adrenocortical tumors. Urology. 2001;57:176-82.

71. Stojadinovic A, Brennan MF, Hoos A, Omeroglu A, Leung DHY, Dudas ME, et al. Adrenocortical adenoma and carcinoma: histopathological and molecular comparative analysis. Mod Pathol. 2003;16:742-51.

72. Tritos NA, Cushing GW, Heatley G, Libertino JA. Clinical features and prognostic factors associated with adrenocortical carcinoma: Lahey Clinic Medical Center experience. Am Surg. 2000;66:73-9. 
73. Zini L, Capitanio U, Jeldres C, Lughezzani G, Sun M, Shariat SF, et al. External validation of a nomogram predicting mortality in patients with adrenocortical carcinoma. BJUI. 2009;104:1661-7.

74. Okazumi S, Asano T, Ryu M, Nagashima T, Odaka M, Isono K, et al. Surgical resection of adrenal carcinoma extending into the vena cava, right atrium and ventricle: case report and review of the literature [abstract]. Nihon Geka Gakkai Zasshi. 1987;88:231-8.

75. Collina G, Maldarizzi F, Betts CM, Eusebi V. Primary sarcomatoid carcinoma of the adrenal gland: first case report. Virchows Archiv A Pathol Anat. 1989;415:161-7.

76. Decorato JW, Gruber H, Petti M, Levowitz BS. Adrenal carcinosarcoma. J Surg Oncol. 1990;45:134-6.

77. Fischler DF, Nunez C, Levin HS, McMaon JT, Sheeler LR, Adelstein DJ. Adrenal carcinosarcoma presenting in a woman with clinical signs of virilization. Am J Surg Pathol. 1992;16:626-31.

78. Barksdale SK, Marincola FM, Jaffe G. Carcinosarcoma of the adrenal cortex presenting with mineralocorticoid excess. Am J Surg Pathol. 1993;17:941-5.

79. Lee MS, Park IA, Chi JG, Ham EK, Lee KC, Lee CW. Adrenal carcinosarcoma: a case report. JKMS. 1997;12:374-7.

80. Coli A, Di Giorgio A, Castri F, Destito C, Marin AW, Bigotti G. Sarcomatoid carcinoma of the adrenal gland: a case report and review of the literature. Pathol Res Pract. 2010;206:59-65.

81. Feng Y, Yang Z, Chen T, Su X, Deng W, Wang Q. Adrenal sarcomatoid carcinoma: a rare case depicted on multi-detector row computer tomography. Indian J Med Sci. 2010;64:37-40.

82. Sasaki K, Desimone M, Rao HR, Huang GJ, Seethala RR. Adrenocortical carcinosarcoma: a case report and review of the literature. Diagn Pathol. 2010;5:51.

83. Bertolini F, Rossi G, Fiocchi F, Giacometti M, Fontana A, Gibertini MC, et al. Primary adrenal gland carcinosarcoma associated with metastatic rectal cancer: a hitherto unreported collision tumor. Tumori. 2011;97:e27-30.

84. Thway K, Olmos D, Shah C, Flora R, Shipley J, Fisher C. Oncocytic adrenal cortical carcinosarcoma with pleomorphic rhabdomyosarcomatous metastases. Am J Surg Pathol. 2012;36:470-7.

85. Yan J, Sun A, Ren Y, Hou C. Primary adrenocortical sarcomatoid carcinoma: report of a case. Can Urol Assoc J. 2012;6:e189-91.

86. Kao C, Grignon DJ, Ulbright TM, Idrees MT. A case report of adrenocortical carcinosarcoma with oncocytic and primitive neuroectodermal-like features. Hum Pathol. 2013:44:1947-55.

87. Mark D, Boyd C, Eatock F. Adrenal sarcomatoid carcinoma: a case report and review of the literature. Ulster Med J. 2014;83:89-92.

88. Shaikh AS, Bakhshi GD, Khan AS, Jamadar NM, Nirmala AK, Raza AA. Primary adrenal sarcomatoid carcinoma. Clin Pract. 2014;4:604.

\section{Submit your next manuscript to BioMed Central and take full advantage of:}

- Convenient online submission

- Thorough peer review

- No space constraints or color figure charges

- Immediate publication on acceptance

- Inclusion in PubMed, CAS, Scopus and Google Scholar

- Research which is freely available for redistribution 